\title{
Introducing CDIO Elements into Preparing of Students of the Faculty of Chemistry of Astrakhan State University for Innovative Activity
}

\author{
A.G. Tyrkov, O.S. Sadomtseva, A.V. Velikorodov, E.F. Matveeva, \\ V.V. Shakirova, A.M. Salmahaeva \\ Astrakhan State University
}

\begin{abstract}
The objective of the research realization was the study, analysis and forecasting of a possibility to apply the CDIO Standards in preparing of Bachelors and Masters of Chemistry at Astrakhan State University (Russia) to innovation activity in industrial enterprises.

The results of the research are the following: revision of the educational curricula, improvement of teaching discipline complexes, introduction of new training courses; realization of the project on establishment of a common educational medium «School - University».

The results have been achieved by application of methods of monitoring over professional competences and quality of training of professionals demanded at the modern labor market and involving of the trainees in project activity, and by involvement of students into the project activity.
\end{abstract}

\section{Introduction}

University graduates are not often ready for working in industries and face great difficulties. Despite the theoretical knowledge and the acquired by the time practical skills, there is still a gap between the requirements of academic training and those of industrial field. It usually takes much time for a graduate to adapt and the company has to refuse him a job or invest extra-resources into his training.

The employers are getting more interested in hiring top-ranked and competent professionals. Attracting them they tend to organize special laboratories for creating a team of fellow thinkers in technological projects development, for example Production Commercial Firm Sardonyx Ltd. in Astrakhan. Graduates and second year Master students of the Faculty of Chemistry work there; they are united by a common technological task corresponding to the Worldwide CDIO Initiative [1].

The Initiative's rational kernel consists in the consequence of three objectives:

1) deep practical knowledge of the pro fession technical bases;

2) proficiency in creating and operating new products and systems;

3) understanding of importance and strategic knowing of scientific and technical society development.

Nowadays there is a decline in students' interest in scientific disciplines, including Chemistry, and Russia is not exclusion. Furthermore the training standards of the third generation have been realized in Russia since 2011, and the standards provide up to $30 \%$ of class hours in active and interactive forms of training. Not less than $5 \%$ of the curriculum disciplines should be realized with 
employers' involvement in order to strengthen the practical constituent of the studying process.

Astrakhan State University has joined the Worldwide CDIO Initiative considering it to be a context of professional education.

\section{Elements of CDIO technology in education process}

Astrakhan State University has joined the Worldwide CDIO Initiative considering it to be a context of professional education.

The CDIO Initiative includes 12 standards of educational programmes, which are a sort of guidelines for educational reforms and evaluation of their efficiency [2].

Resulting from Russia's switching to a new level of market relations development there is a need for professionals capable of generating new ideas, designing, implementing and operating innovative technologies.

A system of training professionals capable of solving the above mentioned tasks has been in realization at the Faculty of Chemistry for a number of years already.

The system comprises the following stages:

1) Training of schoolchildren at the faculty vocational schools with the aim of attracting talented young people, stimulating interest for studying Chemistry bases as well as solving scientific and technical problems;

2) Training of Bachelors of Chemistry as specified in the integrated curriculum comprising complementary studying disciplines which allows to combine in training both personal and interpersonal skills, as well as skills for designing products and systems in accordance with the CDIO Standard 3;

3) Within the frameworks of the existing at the faculty Master's Programmes we solve tasks for training professionals realizing new approaches to Chemistry as to a science capable to provide designing, production and consumption of environmentally friendly chemical products at all the stages of the chemical process.

As well as other University departments, the Faculty of Chemistry realizes a project aimed at creation of a common educational medium called "SchoolUniversity", which presupposes involvement of the Astrakhan region educational institutions into the University programmes by the use of informational technologies.

The project is aimed at the following targets [3]:

- creation of informational and methodological medium of the "SchoolUniversity" system, digital educational resources and guidance manual data-base of the new generation, available for teachers and students;

- providing of real time access for schoolchildren, teachers, leaders of educational institutions, teachers of institutions of additional education to informational resources dealing with the content, innovation forms, methods and technologies of education;

- development of new methods of outer class creative work with students;

- providing of conditions for the phased transition to a new educational level on the basis of informational technologies;

further training of teachers; complex and systematic application of informational and communicative technologies in city educational systems;

- creation and development of a unique virtual educational and informational medium in the Astrakhan region, which will provide for integration of educational institutions into a common educational space of Russia. 
The chemical vocational schools may attend pupils of the $9^{\text {th }}-11^{\text {th }}$ forms of comprehensive schools, gymnasiums and lyceums of the Astrakhan region with different levels of knowledge.

The proposed training system generates positive personal features, insistence and responsibility for making tasks, striving for cooperation.

When in the $11^{\text {th }}$ form the pupils maintain their research-scientific work and receive a certificate for a successful graduation from the vocational school. Our experience suggests that the vast majority of the chemical vocational school graduates enter the Faculty of Chemistry of Astrakhan State University and become successful students. Having started the project activity at the vocational school they continue the work on a higher university level.

The curricula of the Bachelor's and Master's Programmes are aimed at generation of professional skills coherent with the employers taking an active part in the educational process.

The University training system provides for realization of the students' ideas having practical orientation. Apart from the disciplines of the professional cycle, the curriculum pays much attention to the learning of foreign languages, and principles of marketing, fundraising, management and philosophy of lean thinking [4]. According to the CDIO Standard 6 the resource base of the Faculty of Chemistry possesses classrooms and laboratories providing everything needed for training skills of designing and developing of products and systems, and transfer of disciplinary knowledge.

In accordance with the CDIO Standard 5 the students of the Faculty of Chemistry, within the frameworks of the CDIO Initiative, receive financial support for practical realization of their projects.

The implementation of the Worldwide CDIO Initiative Standards allows to re- build the structure of educational process, basing it on permanent activation of the students' learning activity, which has eventually helped the faculty student teams to design new types of products (pharmaceutical substance Immunoflan, pumpkin and watermelon seeds oil, volatile oils of a number of endemic plants of the Astrakhan region, etc.).

The knowledge of foreign languages gives the students a possibility to participate in inclusive educational programmes at leading Universities in France, Italy, Germany and the USA.

\section{Conclusion}

Our experience suggests that the Worldwide CDIO Initiative Standards implementation into the practice of university education and generation of lean thinking among students and teachers allow to develop innovative activity of a higher educational institution, including the establishment of Techno Park, innovation centers, small innovation enterprises, as well as to promote interaction with small, medium-sized and large businesses through execution of agricultural contract works; involvement of the students into patentinnovative and industrial processes.

\section{References}

[1] E.F. Crawley. The CDIO Syllabus Report - A Statement of Goals for Undergraduate Engineering Education, Massachusetts Institute of Technology, Department of Aeronautics and Astronautics, Cambridge, Massachusetts, 2001.

[2] A.M. Treshchev, O.A. Sergeeva The Worldwide CDIO Initiative as a context of professional education. Modern problems of science and education. 2012, No.2 (http://www.scienceeducation.ru/pdf/2012/4/82.pdf). 
[3] E.F. Matveeva, R.R. Nasirov About learning to science-based forecasting. Chemistry at high school. 2012, No.8, P.35-39.

[4] E.A. Moldavskaya, A.M. Treshchev
Adaptation of the lean production concept at a self-educating organization. Business. Education. Right. Vestnik of Volgograd Business Institute. 2012, No.1, P.199-202. 